\title{
End-expiratory occlusion maneuver to predict fluid responsiveness in the intensive care unit: an echocardiographic study
}

Delphine Georges ${ }^{1}$, Hugues de Courson ${ }^{1}$, Romain Lanchon ${ }^{1}$, Musa Sesay ${ }^{1}$, Karine Nouette-Gaulain ${ }^{1,2,3}$ and Matthieu Biais ${ }^{1,3,4^{*}}$

\begin{abstract}
Background: In mechanically ventilated patients, an increase in cardiac index during an end-expiratory-occlusion test predicts fluid responsiveness. To identify this rapid increase in cardiac index, continuous and instantaneous cardiac index monitoring is necessary, decreasing its feasibility at the bedside. Our study was designed to investigate whether changes in velocity time integral and in peak velocity obtained using transthoracic echocardiography during an end-expiratory-occlusion maneuver could predict fluid responsiveness.

Methods: This single-center, prospective study included 50 mechanically ventilated critically ill patients. Velocity time integral and peak velocity were assessed using transthoracic echocardiography before and at the end of a 12-sec end-expiratory-occlusion maneuver. A third set of measurements was performed after volume expansion (500 $\mathrm{mL}$ of saline $0.9 \%$ given over 15 minutes). Patients were considered as responders if cardiac output increased by $15 \%$ or more after volume expansion.
\end{abstract}

Results: Twenty-eight patients were responders. At baseline, heart rate, mean arterial pressure, cardiac output, velocity time integral and peak velocity were similar between responders and non-responders. End-expiratoryocclusion maneuver induced a significant increase in velocity time integral both in responders and non-responders, and a significant increase in peak velocity only in responders. A 9\% increase in velocity time integral induced by the end-expiratory-occlusion maneuver predicted fluid responsiveness with sensitivity of 89\% (95\% Cl 72\% to 98\%) and specificity of $95 \%$ (95\% Cl 77\% to 100\%). An $8.5 \%$ increase in peak velocity induced by the end-expiratory-occlusion maneuver predicted fluid responsiveness with sensitivity of $64 \%$ (95\% Cl $44 \%$ to $81 \%$ ) and specificity of $77 \%$ (95\% Cl 55\% to 92\%). The area under the receiver operating curve generated for changes in velocity time integral was significantly higher than the one generated for changes in peak velocity $(0.96 \pm 0.03$ versus $0.70 \pm 0.07$, respectively, $P=0.0004$ for both). The gray zone ranged between 6 and $10 \%$ (20\% of the patients) for changes in velocity time integral and between 1 and 13\% (62\% of the patients) for changes in peak velocity.

Conclusions: In mechanically ventilated and sedated patients in the neuro Intensive Care Unit, changes in velocity time integral during a 12-sec end-expiratory-occlusion maneuver were able to predict fluid responsiveness and perform better than changes in peak velocity.

Keywords: Fluid responsiveness, End-expiratory occlusion, Heart-lung interactions, Volume expansion, Echocardiography

\footnotetext{
* Correspondence: matthieu.biais@chu-bordeaux.fr

${ }^{1}$ Department of Anesthesiology and Critical Care Pellegrin, Bordeaux

University Hospital, F-33000 Bordeaux, France

${ }^{3}$ University of Bordeaux, Bordeaux F-33600, France

Full list of author information is available at the end of the article
} 


\section{Background}

Management of fluid administration is of major importance in the intensive care unit (ICU) and particularly in the neuro-ICU. On the one hand, hypovolemia may lead to organ dysfunction and on the other hand positive cumulative fluid balance is associated with an increase in both morbidity and mortality [1]. Recent studies underline the heterogeneity of practice and the uncommon prediction of fluid responsiveness before volume expansion $[2,3]$. Dynamic parameters such as pulse pressure variations and stroke volume variations are very robust parameters but many limitations have been described in the ICU [4-6]. New approaches (evaluation of the effects of a transient increase in tidal volume, of a lung recruitment maneuver or an end-expiratory occlusion (EEO) test) have been developed [7-9].

Monnet et al. were the first to investigate the possibility of predicting fluid responsiveness by analyzing the effects of an EEO [8]. In patients under mechanical ventilation, the inspiratory phase increases intra-thoracic pressure and decreases venous return. EEO prevents any variation in intra-thoracic pressure. This leads to an increase in venous return, cardiac preload and stroke volume in preload-responsive patients. Thus, an increase in cardiac index during an EEO could predict fluid responsiveness. In order to identify the rapid and transient increase in cardiac index during the EEO, continuous and instantaneous cardiac index monitoring is necessary (pulse contour analysis was used in ICU studies).

Transthoracic echocardiography is routinely used in the ICU and may allow continuous measurements of stroke volume and cardiac output [10]. In patients who do not benefit from continuous cardiac output monitoring, echocardiography could be an interesting alternative to track changes in stroke volume or cardiac output [11]. The aim of the present study was to investigate whether changes in velocity time integral (VTI) and peak velocity (Vmax) during an EEO could predict fluid responsiveness in mechanically ventilated ICU patients.

\section{Methods}

\section{Patients}

The present study was approved by the Institutional Review Board (Comité de Protection des Personnes Sud-Ouest et Outre Mer III, Bordeaux, France number DC2016/14). Fifty non-consecutive patients were prospectively included after informed consent from the patient's next of kin. Inclusion criteria were sedated and mechanically ventilated patients for whom the decision to perform volume expansion was taken by the physician (arterial hypotension, oliguria less than $0.5 \mathrm{ml} / \mathrm{kg} / \mathrm{h}$, skin mottling, attempt to decrease vasopressor infusion rate). Patients were not included if they were younger than 18 years, presented with unsatisfactory cardiac echogenicity, chronic arrhythmia, significant valvular heart disease, intracardiac shunt, left ventricular ejection fraction $<50 \%$, right ventricular dysfunction (attested by a peak systolic velocity of tricuspid annular motion $<0.15 \mathrm{~m} / \mathrm{s}$ ) or intra-cranial hypertension or spontaneous breathing activity.

\section{Hemodynamic monitoring}

All echocardiographic measurements were performed by two experienced physicians (level 2 or 3 ) who were unaware of the clinical data (DG and MB), using a General Electric Vivid S6 machine (GE Healthcare, Wauwatosa, WI, USA). Videos were anonymously recorded for blinded and offline measurements, by a single observer (DG). Using the 5-chamber apical view, the VTI was measured from the area under the envelope of the pulsed-wave Doppler signal obtained at the level of the aortic annulus. The VTI and Vmax values were averaged over five consecutive measurements and were manually traced. Using the parasternal long axis view, The diameter of the aortic cusp was measured during systolic time, using the parasternal long axis view. Aortic valve area was calculated as follow: ( $\pi$ diameter ${ }^{2} / 4$ ). Stroke volume was calculated as the product of VTI by aortic valve area. Cardiac output was calculated as the product by stroke volume and heart rate. Using the apical 2-chamber and 4-chamber views, Simpson's biplane was used to measure left ventricular ejection fraction.

The reproducibility of VTI and Vmax were assessed before the study. To limit the effects of respiratory-induced changes in VTI and Vmax, each VTI and Vmax value was obtained as an average over five consecutive measurements. VTI and Vmax values were obtained twice in ten patients by the same operator (DG; intra-observer reproducibility) and a second observer (MB; inter-observer reproducibility). The absolute mean difference was calculated and divided by the mean of the two values. Intra-observer variability was $5 \pm 1 \%$ for VTI and $6 \pm 2 \%$ for Vmax. Interobserver variability was $4 \pm 2 \%$ for VTI and $6 \pm 2 \%$ for Vmax. We calculated the last significant changes as previously described [12]. Briefly, the coefficient of variation may be assimilated to intra-observer variability. The coefficient of error was calculated as the coefficient of variation divided by $\sqrt{ } \mathrm{n}(n=$ number of replicates of measurements in each patient). Finally, the least significant change was calculated as:

$$
\text { Coefficient of error } \times 1.96 \times \sqrt{ } 2
$$

The least significant change was $9.8 \%$ for VTI and $11.8 \%$ for Vmax.

\section{Respiratory parameters}

Patients were ventilated in the volume control mode (Servo-U, Maquet Medical System, Wayne, NJ, USA). 
Tidal volume was set between 6 and $8 \mathrm{~mL} / \mathrm{kg}$ of ideal body weight. End-expiratory occlusion has been extensively described elsewhere. Briefly, it was performed by interrupting the ventilator at end-expiration over $12 \mathrm{sec}$ using the automatic and specific device of the ventilator (total positive end-expiratory pressure). An investigator observed the curves displayed on the ventilator to ensure the absence of spontaneous breathing effort during the end-expiratory occlusion maneuver.

\section{Study design}

All patients were in supine position (trunk elevated $30^{\circ}$ ), sedated and mechanically ventilated. Three sets of measurements were performed. The first set was baseline and included heart rate, arterial pressure, left ventricular ejection fraction, diameter of the aortic cusp, VTI and Vmax measurements. We considered the diameter of the aortic cusp constant during the study protocol. The second set was performed at the end of a 12-sec endexpiratory occlusion maneuver. At this time, heart rate, arterial pressure, VTI and Vmax measurements were recorded (the measurement were performed on the last five cycles before the end of EEO). After the end of the end-expiratory occlusion maneuver, volume expansion was performed using $500 \mathrm{~mL}$ of saline $0.9 \%$ over $15 \mathrm{mi}$ nutes. A third set of measurements was performed immediately after the end of the fluid administration. This set included heart rate, arterial pressure and VTI and Vmax measurements. The VTI and Vmax values were averaged over five consecutive measurements.

\section{Statistical analysis}

Normality was tested using the d'Agostino-Pearson test. Data were expressed as median (25th-75th percentile) or mean (standard derivation, SD) as appropriate. Differences between hemodynamic variables were evaluated with the Wilcoxon test or $t$ test as appropriate. Response to volume expansion was defined as an increase in cardiac output of $15 \%$ or more $[4,13]$. Receiver operating characteristic (ROC) curves were generated to evaluate the ability of percentage changes in VTI and Vmax induced by a 12 -sec end-expiratory occlusion maneuver to predict a fluid-induced increase in cardiac output $\geq 15 \%$. The ROC curves were compared using the DeLong test [14]. The best threshold value was chosen so as to maximize the Youden Index (specificity + sensitivity -1 ). In order to avoid the binary response provided by the ROC curves and to take into account an overlap between responders and non-responders, a gray zone was determined for changes in VTI and changes in Vmax. The gray zone was constructed using a two-step procedure. First, a bootstrap resampling method was applied on changes in VTI and Vmax data. The best threshold of 1000 bootstrapped populations and its 95\% CI were chosen for each variable. Second, we determined the values for which no conclusive information on fluid responsiveness (i.e., cutoff values with sensitivity $<90 \%$ or specificity $<90 \%$ (diagnostic tolerance of $10 \%$ ) could be provided. The gray zone was defined as the values that did not allow a $10 \%$ diagnostic tolerance. Nevertheless, if the characteristics of the study population produced a $95 \% \mathrm{CI}$ of the best thresholds larger than the inconclusive zone, the values obtained during the first step were retained as the gray zone. A diagnostic test is considered to have good accuracy when its area under the ROC curve is $\geq 0.75$ [15]. Fifty patients were necessary to demonstrate the ability of EEO to predict fluid responsiveness with good accuracy, i.e., area under the ROC curve is $\geq 0.75$ (type I error of $5 \%$ and type II error of $10 \%$ ).

Table 1 Main characteristics of patients

\begin{tabular}{|c|c|c|}
\hline Characteristics & $\begin{array}{l}\text { Responders } \\
n=28\end{array}$ & $\begin{array}{l}\text { Non-responders } \\
n=22\end{array}$ \\
\hline Age (years) & $54 \pm 13$ & $53 \pm 14$ \\
\hline Sex, male/female $(n)$ & $16 / 12$ & $10 / 12$ \\
\hline Height (cm) & $170 \pm 9$ & $169 \pm 10$ \\
\hline Weight (kg) & $77 \pm 15$ & $72 \pm 17$ \\
\hline SAPS $\|$ & $46 \pm 17$ & $46 \pm 14$ \\
\hline $\begin{array}{l}\text { Tidal volume ( } \mathrm{mL} . \mathrm{kg}^{-1} \text { of } \\
\text { predicted body weight) }\end{array}$ & $6.9 \pm 0.7$ & $6.8 \pm 0.8$ \\
\hline Respiratory rate (breath. $\min ^{-1}$ ) & $17 \pm 5$ & $16 \pm 3$ \\
\hline $\begin{array}{l}\text { Positive end-expiratory pressure } \\
\left(\mathrm{cmH}_{2} \mathrm{O}\right)\end{array}$ & $6 \pm 2$ & $6 \pm 1$ \\
\hline Driving pressure $\left(\mathrm{cmH}_{2} \mathrm{O}\right)$ & $10 \pm 3$ & $10 \pm 4$ \\
\hline $\begin{array}{l}\text { Compliance of the respiratory } \\
\text { system }\left(\mathrm{mL} / \mathrm{cmH}_{2} \mathrm{O}\right)\end{array}$ & $49 \pm 17$ & $51 \pm 18$ \\
\hline $\mathrm{PaO}_{2} / \mathrm{FiO}_{2}$ & $294 \pm 125$ & $300 \pm 126$ \\
\hline \multicolumn{3}{|l|}{ Etiology of disease on ICU admission } \\
\hline Subarachnoid hemorrhage ( $n$ ) & 14 & 12 \\
\hline Intracerebral hemorrhage $(n)$ & 5 & 6 \\
\hline Ischemic stroke $(n)$ & 5 & 1 \\
\hline Other $(n)$ & 4 & 3 \\
\hline \multicolumn{3}{|l|}{ Etiology of volume expansion } \\
\hline $\begin{array}{l}\text { Need to increase mean arterial } \\
\text { pressure }(n)\end{array}$ & 19 & 12 \\
\hline Oliguria $(n)$ & 2 & 7 \\
\hline Tachycardia $(n)$ & 7 & 3 \\
\hline Left ventricular ejection fraction (\%) & $55 \pm 9$ & $56 \pm 9$ \\
\hline Norepinephrine $(n(\%))$ & $25(89 \%)$ & $22(100 \%)$ \\
\hline $\begin{array}{l}\text { Dosage of norepinephrine } \\
\left(\mu \mathrm{g} \cdot \mathrm{kg}^{-1} \cdot \mathrm{min}^{-1}\right)\end{array}$ & $0.49(0.19-1.5)$ & $0.90(0.5-1.80)$ \\
\hline
\end{tabular}

Values are mean $\pm \mathrm{SD}$, number of patients $(n)$ or median (interquartile range (25-75\%)) as appropriate

ICU Intensive Care Unit, SAPS II Simplified Acute Physiologic Score, $\mathrm{PaO}_{2} / \mathrm{FiO}_{2}$ ratio of arterial oxygen tension to inspired oxygen fraction 
Statistical analysis was performed using MedCalc (Version 14.12.0, MedCalc Software bvba, Belgium). A $P$ value $<0.05$ was used for statistical significance.

\section{Results}

\section{Patients}

Fifty non-consecutive patients were included. The main characteristics of patients are reported in Table 1. The main etiology of ICU admission was subarachnoid hemorrhage. A large majority (94\%) of patients received norepinephrine and none of them received other vasopressors or inotropes. Left ventricular ejection fraction was higher than $50 \%$ in both responders and nonresponders.

\section{Effects of EEO and volume expansion}

EEO induced a significant increase in VTI $(19 \%$ in responders and 5\% in non-responders), in Vmax (10\% in responders and in $4 \%$ non-responders), in stroke volume (18\% in responders and $4 \%$ in non-responders) and cardiac output $(20 \%$ in responders and $6 \%$ in nonresponders). Volume expansion induced a significant increase in mean arterial pressure, VTI, stroke volume and cardiac output in both responders and non- responders. Volume expansion induced an increase in Vmax only in responders (Table 2).

\section{Prediction of fluid responsiveness}

The main results on the prediction of fluid responsiveness are shown in Figs. 1, 2 and Table 3. A 9\% increase in VTI induced by the EEO predicted fluid responsiveness with sensitivity of $89 \%$ (95\% CI $72 \%$ to $98 \%)$ and specificity of $95 \%$ (95\% CI $77 \%$ to $100 \%$ ). An $8.5 \%$ increase in peak velocity induced by the EEO maneuver predicted fluid responsiveness with sensitivity of $64 \%$ (95\% CI $44 \%$ to $77 \%$ ) and specificity of $77 \%$ (95\% CI 55\% to $92 \%)$. The area under the ROC curve generated for changes in VTI was significantly higher than the one generated for changes in peak velocity $(0.96 \pm 0.03$ versus $0.70 \pm 0.07$, respectively, $P=P=0.0004$ ). The gray zone ranged between 6 and 10\% (20\% of the patients) for changes in VTI and between 1 and 13\% (62\% of the patients) for changes in Vmax (Fig. 3).

\section{Discussion}

Our study suggests, in mechanically ventilated neuroICU patients that: (1) EEO induces an increase in VTI and Vmax; (2) a 9\% increase in VTI induced by the end-expiratory-occlusion maneuver predicted fluid

Table 2 Hemodynamic variables at baseline, at the end of the end-expiratory occlusion test and after volume expansion in responders $(n=28)$ and non-responders $(n=22)$

\begin{tabular}{|c|c|c|c|c|c|}
\hline Variables & Baseline & EEO & After VE & $P 1$ & $P 2$ \\
\hline \multicolumn{6}{|l|}{ Heart rate (bpm) } \\
\hline Responders & $71 \pm 17$ & $71 \pm 16$ & $73 \pm 16$ & 0.59 & 0.006 \\
\hline Non-responders & $74 \pm 18$ & $74 \pm 17$ & $74 \pm 18$ & 0.99 & 0.8 \\
\hline \multicolumn{6}{|c|}{ Mean arterial pressure $(\mathrm{mmHg})$} \\
\hline Responders & $82 \pm 15$ & $91 \pm 11$ & $94 \pm 16$ & 0.34 & 0.0001 \\
\hline Non-responders & $85 \pm 12$ & $85 \pm 14$ & $96 \pm 13$ & 0.18 & 0.0002 \\
\hline \multicolumn{6}{|c|}{ Cardiac output (I/min) } \\
\hline Responders & 5. $1 \pm 2.0$ & $6.1 \pm 2.8$ & $6.4 \pm 2.7$ & $<0.0001$ & $<0.0001$ \\
\hline Non-responders & $5.0 \pm 1.6$ & $5.3 \pm 1.8$ & $5.3 \pm 1.6$ & 0.0006 & 0.006 \\
\hline \multicolumn{6}{|l|}{ Stroke volume (mL) } \\
\hline Responders & $72 \pm 20$ & $85 \pm 29$ & $87 \pm 28$ & $<0.0001$ & $<0.0001$ \\
\hline Non-responders & $70 \pm 23$ & $73 \pm 23$ & $73 \pm 23$ & 0.0012 & 0.02 \\
\hline \multicolumn{6}{|c|}{ Velocity time integral (cm) } \\
\hline Responders & $21 \pm 5$ & $25 \pm 5$ & $25 \pm 5$ & $<0.0001$ & $<0.0001$ \\
\hline Non-responders & $21 \pm 4$ & $22 \pm 4$ & $22 \pm 5$ & 0.0001 & 0.01 \\
\hline \multicolumn{6}{|l|}{ Vmax (cm/sec) } \\
\hline Responders & $1.13 \pm 0.26$ & $1.25 \pm 0.30$ & $1.27 \pm 0.3$ & $<0.0001$ & $<0.0001$ \\
\hline Non-responders & $1.10 \pm 0.25$ & $1.15 \pm 0.24$ & $1.15 \pm 0.23$ & $<0.001$ & $<0.05$ \\
\hline
\end{tabular}

Values are mean \pm standard deviation. Patients were considered responders if stroke volume increased by $\geq 10 \%$ after $250 \mathrm{~mL}$ intravascular volume expansion. Baseline was before end-expiratory occlusion (EEO). The EEO measurements were made at the end of 12-sec EEO. After VE measurements made immediately after volume expansion (VE) $(500 \mathrm{ml}$ saline), $P 1 P$ values for comparison between measurements at baseline and at the end of EEO, $P 2 P$ values for comparison between measurements at baseline and after volume expansion, Vmax peak velocity of aortic blood flow

$P<0.05$ for comparison of responders and non-responders at baseline 


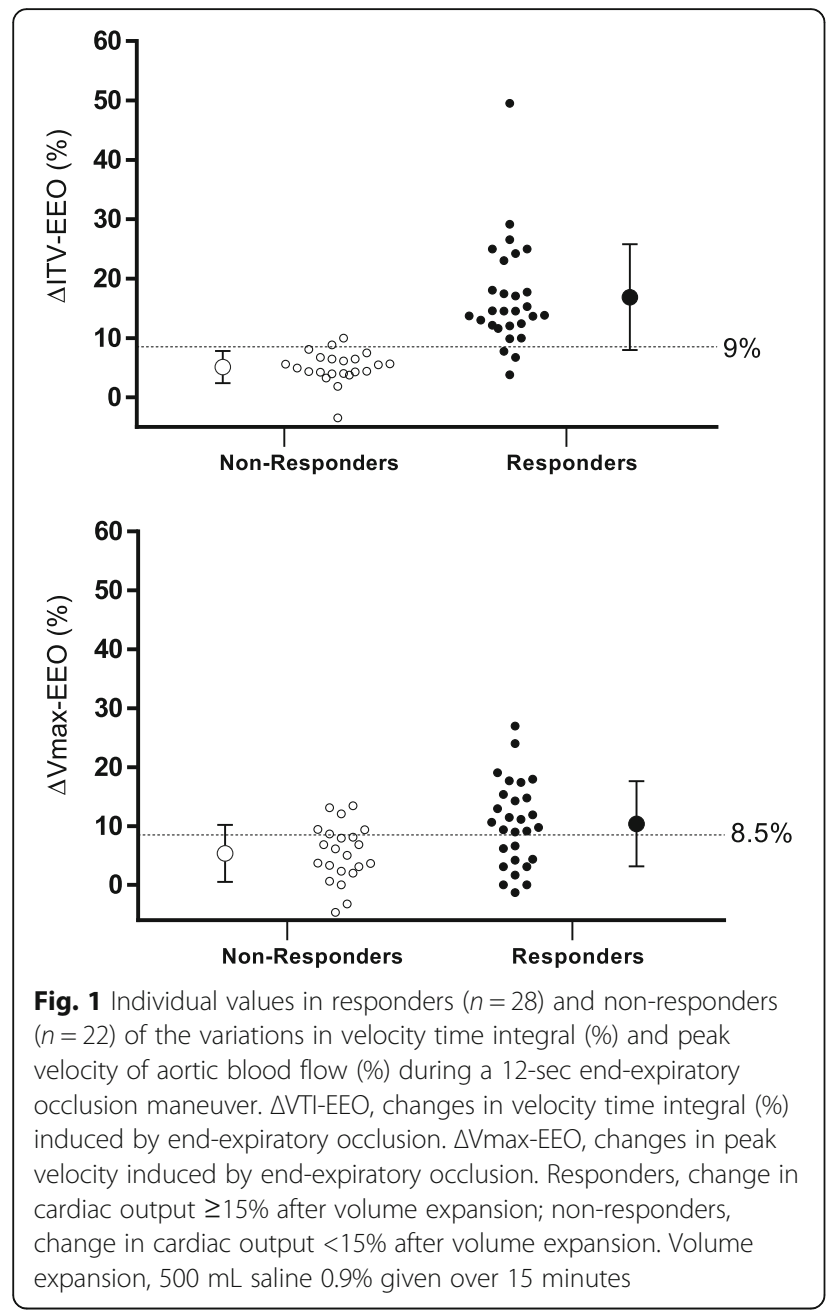

responsiveness with satisfactory sensitivity and specificity; and (3) changes in Vmax induced by EEO performed less effectively than changes in VTI and exhibited a larger gray zone.

Monnet et al. were the first to introduce EEO as a marker of fluid responsiveness [8]. Their first study included 34 mechanically ventilated ICU patients and showed that EEO is able to predict fluid responsiveness with satisfactory sensitivity and specificity even in patients with cardiac arrhythmia or moderate spontaneous breathing activity. Later, the same group demonstrated in patients that EEO remains accurate even in patients suffering from acute respiratory distress syndrome and/or low compliance of the respiratory system [16]. More recently, Myatra et al. included 20 patients and suggested that EEO is able to predict fluid responsiveness in patients ventilated with a tidal volume of $8 \mathrm{~mL} / \mathrm{kg}^{-1}$ of ideal body weight but not in those ventilated with a lower tidal volume $\left(6 \mathrm{~mL} / \mathrm{kg}^{-1}\right.$ of ideal body weight) [7].

The main difference between these studies and ours is that we used transthoracic echocardiography and not pulse contour analysis for cardiac output measurements. A recent

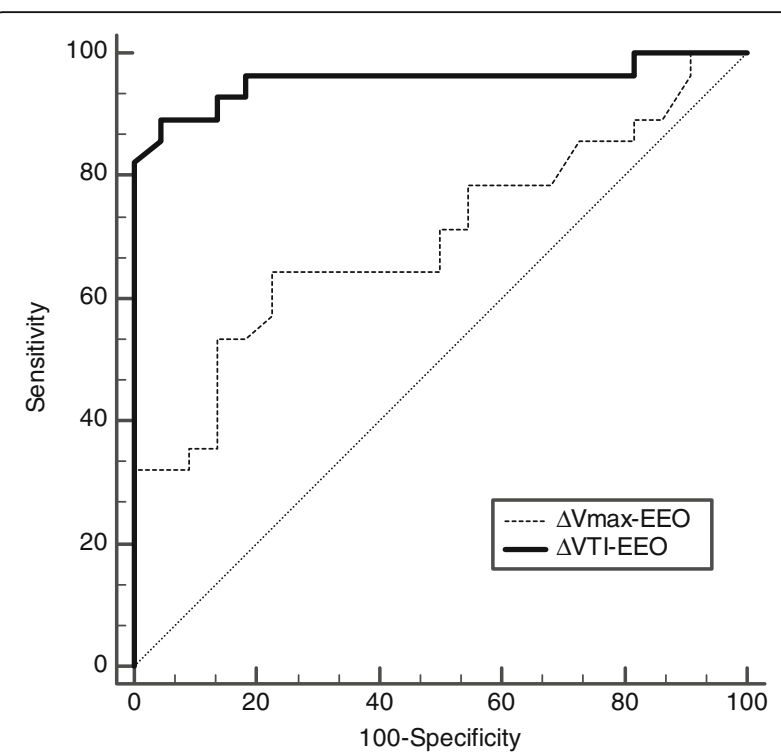

Fig. 2 Receiver operating characteristics curves evaluating the ability of the variations in velocity time integral (\%) and peak velocity of aortic blood flow (\%) during a 12-sec end-expiratory occlusion maneuver to predict fluid responsiveness. $\triangle \mathrm{VTI}$-EEO, changes in velocity time integral (\%) induced by end-expiratory occlusion. $\Delta V \max$, changes in peak velocity induced by end-expiratory occlusion. Responders, change in cardiac output $\geq 15 \%$ after volume expansion; non-responders, change in cardiac output $<15 \%$ after volume expansion. Volume expansion, $500 \mathrm{~mL}$ saline $0.9 \%$ given over 15 minutes

study evaluated the effects of EEO on VTI [17]. Jozwiak et al. included $30 \mathrm{ICU}$ patients and found that a $5 \%$ increase in VTI at the end of a 15-sec EEO predicted fluid responsiveness with good sensitivity and specificity. The authors also demonstrated that when combining the effect of EEO and end-inspiratory occlusion on VTI, the threshold discriminating responders and non-responders increased to $13 \%$. This approach is of interest because combining the effects of EEO and end-inspiratory occlusion on VTI allows us to increase the best threshold value (from 5 to 13\%) and thus, above the variability in the measurements when using echocardiography. In the present study, we found a higher threshold for both VTI and Vmax (9 and 8.5\% respectively). The main difference between these two studies is that the populations are not comparable: different types of patients, hemodynamic baseline values, respiratory parameters, indication of volume expansion, normal compliance of the respiratory system and no acute respiratory distress syndrome in our study, etc. Furthermore, defining thresholds using receiver operating characteristics curves in a small sample needs to take into account the gray zone. Considering VTI, the lower value of the gray zone in our study was very close to best threshold value identified by Jozwiak et al. (6 versus $5 \%$ ). Other studies including more patients would help us to define more precise thresholds. 
Table 3 Ability to predict increase in cardiac output $\geq 15 \%$ after infusion of $500 \mathrm{~mL}$ saline over 15 minutes

\begin{tabular}{llllllll}
\hline Index & Best threshold & Gray zone & $\begin{array}{l}\text { Patients whose measurements } \\
\text { were in the gray zone }\end{array}$ & AUROC (95\% Cl) & Sensitivity (95\% Cl) & Specificity (95\% Cl) & Youden index J \\
\hline$\Delta \mathrm{VTI}$ & $>9 \%$ & $6-10 \%$ & $20 \%$ & $0.96 \pm 0.03$ & $89 \%(72-98 \%)$ & $95 \%(77-100 \%)$ & 0.85 \\
$\Delta \mathrm{V} \max$ & $>8.5 \%$ & $1-13 \%$ & $62 \%$ & $0.70 \pm 0.07$ & $64 \%(44-81 \%)$ & $77 \%(55-92 \%)$ & 0.42 \\
\hline
\end{tabular}

Best threshold value was determined using the Youden index. Youden Index J = Sensitivity + Specificity -1 . $\Delta \mathrm{VTI}$ represents changes in velocity time integral induced by end-expiratory occlusion. $\Delta V$ max represents changes in peak velocity induced by end-expiratory occlusion

$A U R O C$ area under receiver operating characteristics curves, $\mathrm{Cl}$ confidence interval

Echocardiography is useful for diagnosis and management of acute circulatory failure in ICU patients. It allows rapid assessment of the anatomy and function of the heart and it is possible to directly measure absolute values or changes in stroke volume and cardiac output with good accuracy [11]. Echocardiography may also provide the assessment of both the efficacy and tolerance of fluid challenge. VTI is a major determinant of stroke volume which is calculated as the product of VTI and the aortic valve area. Changes in VTI may be used as a surrogate for changes in stroke volume if we consider that aortic valve area is constant $[18,19]$. Some authors propose using changes in $V \max$ as a surrogate for changes in stroke volume [20].

Echocardiography provides very important information to the clinician and is non-invasive. However, some limitations should be emphasized. First, measurements obtained by echocardiography are dependent on the patients' echogenicity. ICU patients under mechanical ventilation are well-known for having lower echogenicity. Unfortunately, we did not record in our study the number of patients with poor echogenicity to perform measurements and who had to be excluded. In the recent study published by Jozwiak et al. $41 \%$ of patients were excluded because they presented with poor echogenicity. Second, specific training is needed. Many studies demonstrate that learning curves are relatively short for basic measurements (including VTI) [10, 21]. Third, measurements are operator dependent. Intra-observer and inter-observer variability reported in previous studies and in ours is close to $4-6 \%[17,22,23]$. This may explain that performance of Vmax was inferior to performance of VTI in the present study. We observed a large gray zone for $V \max (1-13 \%)$ with a lower limit lower than the intra-observer and inter-observer variability, whereas this was not the case for VTI (the gray zone ranged between 6 and 10\%). Nevertheless, when considering a least significant change just below $10 \%$ for VTI measurements in our study, we may have to consider the higher limit of the gray zone $(10 \%)$ for determining the optimal threshold.

Our study presents some limitations. We did not perform a set of measurements before volume expansion. EEOT is a very quick test $(12 \mathrm{sec})$ and all studies investigating the ability of EEOT to predict fluid responsiveness observed that the effects of EEOT were very transient $(<1$ minute) and that all hemodynamic parameters returned to their initial values within 1 minute $[8,16,24]$.
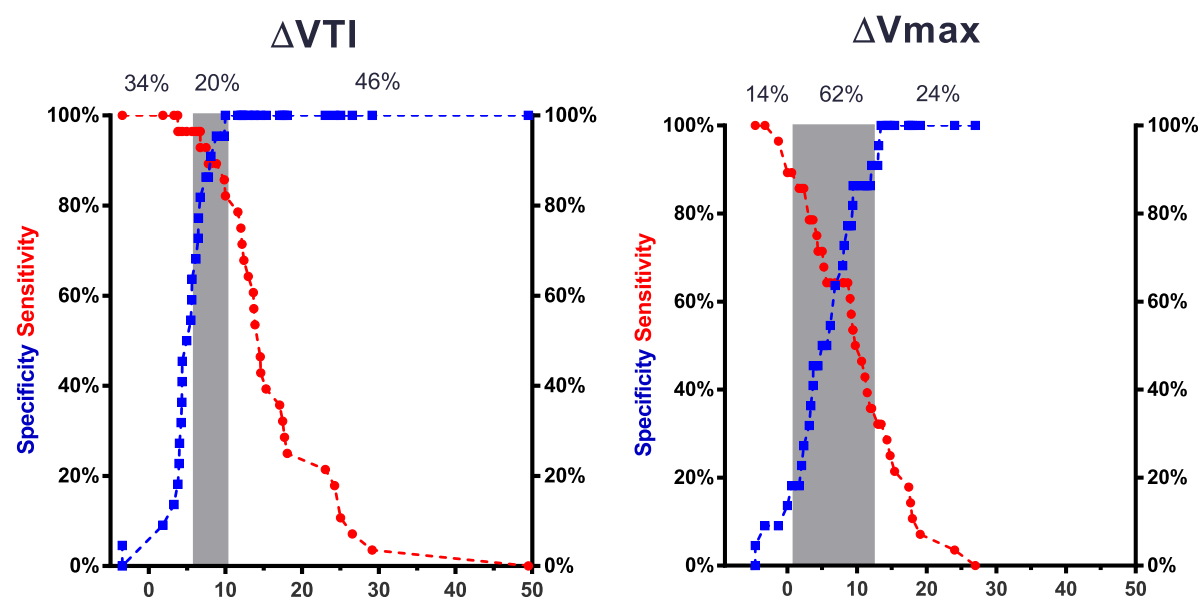

Fig. 3 Gray zone of the variations in velocity time integral (\%) and peak velocity of aortic blood flow (\%) induced by a 12-sec end-expiratory occlusion maneuver to predict fluid responsiveness. The blue curve indicates sensitivity, and the red curve indicates specificity. $\Delta \mathrm{VTI}-\mathrm{EEO}$, changes in velocity time integral (\%) induced by end-expiratory occlusion test. $\Delta V \mathrm{max}$, changes in peak velocity induced by end-expiratory occlusion. Responders, change in cardiac output $\geq 15 \%$ after volume expansion; non-responders, change in cardiac output $<15 \%$ after volume expansion. Volume expansion, $500 \mathrm{~mL}$ saline $0.9 \%$ given over 15 minutes 
We included a small sample $(n=50)$ of selected and non-consecutive patients. A large majority of our patients suffered from subarachnoid hemorrhage and volume expansion was done to increase mean arterial pressure to improve cerebral blood flow. Few of them had sepsis or septic shock. Furthermore, our patients did not suffer from acute respiratory distress syndrome, had normal compliance with the respiratory system and were ventilated using low positive end-expiratory pressure levels $\left(6 \mathrm{cmH}_{2} \mathrm{O}\right)$. This may decrease the impact of our results and decrease the external validity of our study. Nevertheless, our study was able to show that changes in stroke volume induced by an EEO may be assessed using transthoracic echocardiography and that the magnitude of changes in stroke volume may help to predict fluid responsiveness.

\section{Conclusion}

The present study suggests that in mechanically ventilated and sedated ICU patients, changes in stroke volume induced by a 12-sec EEO may be assessed using transthoracic echocardiography. Change in VTI was able to predict fluid responsiveness and performed better than change in Vmax.

\section{Abbreviations \\ Cl: Confidence interval; EEO: End-expiratory occlusion; ICU: Intensive care unit; ROC: Receiver operating characteristics; Vmax: Peak velocity of aortic blood flow; VTI: Velocity time integral}

\section{Acknowledgements}

Not applicable.

\section{Funding}

This study was supported by institutional and departmental funds.

\section{Availability of data and materials}

All data generated or analyzed during this study are included in this published article.

\section{Authors' contributions \\ DG: recruited patients, collected the data, helped analyze the data and helped in writing the manuscript. HdC: helped recruit patients, analyzed the data and helped in writing the manuscript. RL: helped recruit patients, analyzed the data and helped in writing the manuscript. MS: helped analyze the data, helped in writing the manuscript and corrected the English. KNG helped design the study and write the manuscript. MB designed the study, collected the data, performed statistical analysis and wrote the manuscript. All authors approved the final version.}

\section{Ethics approval and consent to participate}

The present study was approved by the Institutional Review Board (Comité de Protection des Personnes Sud-Ouest et Outre Mer III, Bordeaux, France number DC2016/14)

\section{Consent for publication}

The manuscript has been read and its submission approved by all coauthors. Patients were prospectively included after informed consent from the patient's next of kin.

\section{Competing interests}

$M B$ received honoraria from Edwards Lifesciences and Pulsion Medical System as a lecturer. The other authors have no competing interests.

\section{Publisher's note}

Springer Nature remains neutral with regard to jurisdictional claims in published maps and institutional affiliations.

\section{Author details}

${ }^{1}$ Department of Anesthesiology and Critical Care Pellegrin, Bordeaux University Hospital, F-33000 Bordeaux, France. ${ }^{2}$ INSERM, U12-11, Laboratoire de Maladies Rares: Génétique et Métabolisme (MRGM), Bordeaux, France. ${ }^{3}$ University of Bordeaux, Bordeaux F-33600, France. ${ }^{4}$ INSERM, U1034, Biology of Cardiovascular Diseases, F-33600 Pessac, France.

Received: 16 August 2017 Accepted: 27 December 2017

Published online: 08 February 2018

\section{References}

1. Boyd JH, Forbes J, Nakada T, Walley KR, Russell JA. Fluid resuscitation in septic shock: a positive fluid balance and elevated central venous pressure are associated with increased mortality. Crit Care Med. 2011;39:259-65.

2. Cecconi M, Hofer C, Teboul J-L, Pettila V, Wilkman E, Molnar Z, et al. Fluid challenges in intensive care: the FENICE study: a global inception cohort study. Intensive Care Med. 2015;41:1529-37.

3. Boulain T, Boisrame-Helms J, Ehrmann S, Lascarrou J-B, Bouglé A, Chiche A, et al. Volume expansion in the first 4 days of shock: a prospective multicentre study in 19 French intensive care units. Intensive Care Med. 2015;41:248-56

4. Marik PE, Cavallazzi R, Vasu T, Hirani A. Dynamic changes in arterial waveform derived variables and fluid responsiveness in mechanically ventilated patients: a systematic review of the literature. Crit Care Med. 2009:37:2642-7

5. Mahjoub $Y$, Lejeune $V$, Muller $L$, Perbet $S$, Zieleskiewicz L, Bart F, et al. Evaluation of pulse pressure variation validity criteria in critically ill patients: a prospective observational multicentre point-prevalence study. $\mathrm{Br}$ J Anaesth. 2014:112:681-5.

6. Biais M, Ehrmann S, Mari A, Conte B, Mahjoub Y, Desebbe O, et al. Clinical relevance of pulse pressure variations for predicting fluid responsiveness in mechanically ventilated intensive care unit patients: the grey zone approach. Crit Care Lond Engl. 2014;18:587.

7. Myatra SN, Prabu NR, Divatia JV, Monnet X, Kulkarni AP, Teboul J-L. The changes in pulse pressure variation or stroke volume variation after a "tidal volume challenge" reliably predict fluid responsiveness during low tidal volume ventilation. Crit Care Med. 2017;45:415-21.

8. Monnet X, Osman D, Ridel C, Lamia B, Richard C, Teboul J-L. Predicting volume responsiveness by using the end-expiratory occlusion in mechanically ventilated intensive care unit patients. Crit Care Med. 2009:37:951-6.

9. Biais M, Lanchon R, Sesay M, Le Gall L, Pereira B, Futier E, et al. Changes in stroke volume induced by lung recruitment maneuver predict fluid responsiveness in mechanically ventilated patients in the operating room. Anesthesiology. 2017:126:260-7.

10. Vieillard-Baron A, Mayo PH, Vignon P, Cholley B, Slama M, Pinsky MR, et al. Expert Round Table on Echocardiography in ICU. International consensus statement on training standards for advanced critical care echocardiography. Intensive Care Med. 2014;40:654-66.

11. Wetterslev M, Møller-Sørensen $H$, Johansen RR, Perner A. Systematic review of cardiac output measurements by echocardiography vs. thermodilution: the techniques are not interchangeable. Intensive Care Med. 2016:42:1223-33.

12. Monnet X, Persichini R, Ktari M, Jozwiak M, Richard C, Teboul J-L. Precision of the transpulmonary thermodilution measurements. Crit Care Lond Engl. 2011;15:R204.

13. Michard F, Boussat $S$, Chemla D, Anguel N, Mercat A, Lecarpentier $Y$, et al. Relation between respiratory changes in arterial pulse pressure and fluid responsiveness in septic patients with acute circulatory failure. Am J Respir Crit Care Med. 2000;162:134-8.

14. DeLong ER, DeLong DM, Clarke-Pearson DL. Comparing the areas under two or more correlated receiver operating characteristic curves: a nonparametric approach. Biometrics. 1988:44:837-45.

15. Ray $P$, Le Manach $Y$, Riou B, Houle TT. Statistical evaluation of a biomarker Anesthesiology. 2010;112:1023-40.

16. Monnet X, Bleibtreu A, Ferré A, Dres M, Gharbi R, Richard C, et al. Passive leg-raising and end-expiratory occlusion tests perform better than pulse pressure variation in patients with low respiratory system compliance. Crit Care Med. 2012;40:152-7. 
17. Jozwiak M, Depret F, Teboul J-L, Alphonsine J-E, Lai C, Richard C, et al. Predicting fluid responsiveness in critically ill patients by using combined end-expiratory and end-inspiratory occlusions with echocardiography. Crit Care Med. 2017:45:e1131-8.

18. Slama M, Masson H, Teboul J-L, Arnout M-L, Susic D, Frohlich E, et al. Respiratory variations of aortic VTI: a new index of hypovolemia and fluid responsiveness. Am J Physiol Heart Circ Physiol. 2002;283:H1729-33.

19. Lamia B, Ochagavia A, Monnet X, Chemla D, Richard C, Teboul J-L. Echocardiographic prediction of volume responsiveness in critically ill patients with spontaneously breathing activity. Intensive Care Med. 2007;33: 1125-32.

20. Feissel M, Michard F, Mangin I, Ruyer O, Faller JP, Teboul JL. Respiratory changes in aortic blood velocity as an indicator of fluid responsiveness in ventilated patients with septic shock. Chest. 2001;119:867-73.

21. Jozwiak M, Monnet X, Cinotti R, Bontemps F, Reignier J, Belliard G. Prospective assessment of a score for assessing basic critical-care transthoracic echocardiography skills in ventilated critically ill patients. Ann Intensive Care. 2014;4:12.

22. Biais M, Cottenceau V, Stecken L, Jean M, Ottolenghi L, Roullet S, et al. Evaluation of stroke volume variations obtained with the pressure recording analytic method. Crit Care Med. 2012;40:1186-91.

23. Muller L, Toumi M, Bousquet P-J, Riu-Poulenc B, Louart G, Candela D, et al. An increase in aortic blood flow after an infusion of $100 \mathrm{ml}$ colloid over 1 minute can predict fluid responsiveness: the mini-fluid challenge study. Anesthesiology. 2011;115:541-7.

24. Biais M, Larghi M, Henriot J, de Courson H, Sesay M, Nouette-Gaulain K. End-expiratory occlusion test predicts fluid responsiveness in patients with protective ventilation in the operating room. Anesth Analg. 2017;125:1889-95.

\section{Submit your next manuscript to BioMed Central and we will help you at every step:}

- We accept pre-submission inquiries

- Our selector tool helps you to find the most relevant journal

- We provide round the clock customer support

- Convenient online submission

- Thorough peer review

- Inclusion in PubMed and all major indexing services

- Maximum visibility for your research

Submit your manuscript at www.biomedcentral.com/submit

C) Biomed Central 